\title{
Do trauma à possibilidade de uma narrativa: notas sobre a psicanálise em um Batalhão de Polícia Militar
}

\author{
From the trauma to the possibility of a \\ narrative: notes on psychoanalysis in a \\ Military Police Battalion
}

\author{
Fernanda Cabral Samico*1 \\ Marco Antônio Coutinho Jorge*2
}

\begin{abstract}
Este artigo pondera sobre a experiência da pesquisa "Psicanálise Aplicada e a Prática na Comunidade”, a partir dos atendimentos clínicos oferecidos aos policiais do $10^{\circ}$ Batalhão de Polícia Militar do Estado do Rio de Janeiro. Nele pensamos as características particulares do tratamento psicanalítico com policiais, para entender a contingencialidade do manejo possível para o traumático, de forma que se acolha o excesso de gozo presente no testemunho que os policiais trazem sobre seus sintomas e passagens ao ato.
\end{abstract}

Palavras-chave: Psicanálise, polícia, trauma, clínica

*1 Universidade de Vassouras (Vassouras, RJ, Brasil).

*2 Universidade do Estado do Rio de Janeiro - UERJ (Rio de Janeiro, RJ, Brasil) 


\section{ARTIGOS}

Entre dois sujeitos, não há senão a palavra ou a morte, a salvação

ou a lápide.

Colocar a violência no princípio disso que chamamos de "condição humana", sem levar em conta o que ela comporta de destruição da palavra, não leva a lugar algum.

Moustapha Safouan

A psicanálise, muito antes do desenvolvimento de seu corpo teórico, teve seu nascimento na escuta de eventos traumáticos que perpassavam e muitas vezes determinavam os sintomas neuróticos. A partir da tomada da palavra pelo "doente" e da subversão da relação médico-paciente, Freud pôde exercitar um outro modo de escutar. Ao estilo de um arqueólogo - analogia à qual atribuía importância - ele escrutinou as fantasias, as cifrações oníricas e significações inscritas nos sintomas. Peça por peça, osso por osso, a partir do mosaico pulsional de cores libidinais das vivências infantis recalcadas de suas pacientes histéricas, descortinou o funcionamento do inconsciente, sua grande descoberta. Era, desde o início, um trabalho clínico associado à pesquisa e à concepção de uma nova teoria, que tem, talvez por marca de nascença, a característica de avançar a cada novo impasse, a cada novo questionamento. Isso baliza um movimento próprio à psicanálise: a prática sempre interroga a teoria e, com isso, faz com que ela avance. Dessa forma, não é a teoria que determina a intervenção clínica, mas o contrário. É a experiência com o não delimitado, com o enigma inerente às próprias formações do inconsciente, com o seu pathos, que renova o doutrinal psicanalítico.

Este artigo é fiel ao movimento de avanço do campo psicanalítico, no qual pesquisa e clínica coincidem. É um escrito construído a partir de alguns impasses da experiência da pesquisa 
"Psicanálise aplicada e a prática na comunidade" conduzida por nós e desenvolvida com os estagiários-pesquisadores de Terapia Psicanalítica, do Serviço-Escola de Psicologia, ${ }^{2}$ que tem como campo de atuação os atendimentos clínicos oferecidos aos policiais do $10^{\circ}$ Batalhão de Polícia Militar do Estado do Rio de Janeiro (PMERJ). E assim como Freud, a tentativa de fundamentar nossa atuação nos conduziu a investigar na teoria o que comparecia como enigma na experiência.

\section{A corporação}

A PMERJ se caracteriza por ser uma instituição hierarquicamente organizada e disciplinada. Possui uma vida institucional rica em símbolos, mitos, insígnias e outras construções simbólico-imaginárias que dão consistência à visão corporativa de seus membros. Em sua organização, essas construções funcionam como marcadores do que é a estrutura militar, quem pode comandá-la e a quem se deve obedecer. A construção de uma espécie de ethos policial militar transmite potentes referências simbólicas, que são visíveis a qualquer pessoa que se depare com um policial. O esprit de corps encontra-se tão bem introjetado, que seu efeito comparece no gestual dos policiais, no vocabulário e na maneira como ingressam socialmente nos lugares, expressam-se e interagem com as pessoas. Pudemos observar, em nossa pesquisa, o exercício incessante de uma uniformização de ações, de usos do corpo e dos discursos. As diferenças individuais devem ser minimizadas e o policial deve ser um veículo de emissão tão somente de respostas, seja na interação com os superiores ou até mesmo no contato com os cidadãos.

Um dado que também nos interessou repousa sobre a hipervigilância: a vigilância deve ser, acima de tudo, do próprio policial sobre seu próprio corpo. Há a imposição de uma extrema autovigilância na maneira como o policial deve se apresentar aos outros e manter seu asseio pessoal. O efeito disso é a aversão que muitos policiais apresentam em relação ao desleixo e à

${ }^{1}$ (Plataforma Brasil - parecer 796.267 de 03/09/2014)

${ }^{2}$ Serviço de Psicologia Aplicada do curso de Psicologia da Universidade de Vassouras, RJ. 


\section{ARTIGOS}

bagunça. Muitos relatam um particular incômodo sentido em relação às coisas que por ventura estejam fora do lugar ou desalinhadas. Ainda sobre essa autovigilância temos um dado bastante relevante e que muito nos interessa do ponto de vista psicanalítico: na Academia D. João $\mathrm{VI}^{1}$ e nos pavilhões pedagógicos dos batalhões existe um grande espelho, colocado em um local estratégico de forma que todo policial que entrar em alguma sala de aula tenha nele sua imagem refletida. Alguns espelhos ainda possuem a inscrição "Esse espelho reflete você e você a PMERJ". Cada policial aprende, desde cedo, que mantendo os sapatos bem engraxados, a farda impecavelmente limpa e bem passada, o corte de cabelo sempre bem batido, o rosto ausente de barba para um semblante limpo, esta é a forma pela qual se deve apresentar e divulgar a imagem da PMERJ (Muniz, 1999).

Sobre esse ponto, iniciamos aqui uma discussão. Em 1934, o psicólogo belga Henri Wallon (1934/1995) descreveu em pormenores as reações de uma criança pequena diante de sua imagem no espelho. Descobriu que entre os 6 e os 18 meses de idade, toda criança - algumas mais cedo, outras mais tarde - reconhece em dado momento que a sua imagem no espelho corresponde a seu corpo próprio. Tal percepção é acompanhada de algumas reações significativas: em primeiro lugar, a criança se volta para o adulto que está sempre a seu lado nesse momento, solicitando a confirmação de que sua percepção é correta; em seguida, e somente então, a criança dá mostras de realizar que a imagem do espelho corresponde de fato a seu corpo e, nesse momento, manifesta um júbilo intenso jogando a cabecinha para trás, debatendo-se ansiosamente e salivando.

Lacan (1949/1998) associa essa descoberta de Wallon aos estudos de Freud sobre o narcisismo e coloca a pergunta: por que a criança manifesta tanta excitação ao entender a significação da imagem no espelho? E ele responderá a essa pergunta dizendo que a criança obteve nesse instante algo que ela não possuía antes: a unidade corporal. Até aqui seu corpo era vivenciado como um corpo fragmentado, submetido a sensações penosas e angustiantes que parcializavam a sua vivência corporal. Essa é a unidade descrita por Freud (1914/1992c) como a instância do Eu, centrado essencialmente na imagem corporal.

${ }^{3}$ A Academia de Polícia Militar Dom João VI, antiga Escola de Formação de Oficiais - EsFO é uma Escola de Ensino Superior da Polícia Militar do Estado do Rio de Janeiro. 
Em sua teorização sobre o estádio do Espelho, Lacan (1949/1998) aponta a imagem corporal como propícia para um efeito formador e percorre a noção freudiana de identificação para apontar seu papel fundamental na formação do Eu. Será pela via identificatória que a criança antecipará, imaginariamente, a forma de seu corpo em sua totalidade e poderá, a partir de então, construir um primeiro esboço do Eu. Dessa forma, segundo Lacan (1949/1998), devemos

[...] compreender o estádio do espelho como uma identificação, no sentido pleno que a análise atribui a esse termo, ou seja, a transformação produzida no sujeito quando ele assume uma imagem cuja predestinação para esse efeito de fase é suficientemente indicada pelo uso, na teoria, do antigo termo imago. (p. 97)

Contudo, se o Imaginário for entendido a partir da imagem e do processo de identificação, conforme a hipótese lacaniana, podemos afirmar que acarreta também o registro de uma forma de alienação e engodo. Roland Chemama (1995) ressalta que

[...] na relação intersubjetiva, é sempre introduzida alguma coisa fictícia, que nada mais é do que a projeção imaginária de um sobre a tela simples em que o outro se transforma. Esse é o registro do eu na relação dual com tudo aquilo que comporta de desconhecimento, de alienação, de amor e de agressividade, na relação dual. (p. 104)

Como é possível, então, ratificar essa imagem vacilante? Criamos estratégias para tanto. Uma delas se dá a partir daquilo que envelopa o corpo, ou seja, a partir das vestimentas que entram em jogo na construção da imagem corporal. Nesse contexto, percebemos que, por um lado, o corpo para os policiais se apresenta numa reprodução em série de relações especulares, a partir das quais os laços sociais serão norteados por uma espécie de automatismo característico da identificação imaginária. O espelho situado na entrada da corporação pode ser considerado o paradigma da introjeção de uma determinação sobre si que, inclusive, extrapola os muros do batalhão e o uso da farda. É exigido do policial um regime de comportamento que deve ser mantido até mesmo nos espaços mais triviais do convívio social, como uma confraternização ou uma festa infantil. Como salienta Jaqueline Muniz (1999):

$\mathrm{Na}$ administração cotidiana dessa subjetividade parece ser preciso se manter vigilante, em uma espécie de estado existencial de prontidão, jamais perdendo de vista o comprometimento de sempre "honrar a 


\section{ARTIGOS}

farda" "em cada ação realizada", "em cada ideal alcançado", em suma, "em cada exemplo deixado". (p. 100)

A farda é um elemento de destaque e um significante recorrente tanto nos discursos dos policiais com quem mantivemos um laço clínico, quanto com os que estabelecemos diálogos informais. Interpretada como uma capa de herói ou como mortalha, nenhum policial tem uma opinião neutra acerca de sua farda. É nela que estão costurados diversos apetrechos, como uma tarja com o chamado "nome de guerra", as divisas correspondentes aos graus hierárquicos e outras insígnias referentes à trajetória institucional do policial. O capricho com a farda não apenas atende as exigências formais do regulamento disciplinar, mas também responde à preocupação de se apresentar ao mundo de uma forma garbosa e atraente. A subjetivação de cada policial dessa uniformização que a farda produz varia enormemente e se dirige aos mais diversos aspectos de sua vida. Muitos policiais erotizam seu uso e acreditam que a farda os faz mais atraentes aos olhos das mulheres. Já outros asseveram com ênfase que a farda é um estorvo, um lembrete de que são alvos ambulantes da "bandidagem" (sic). Um exemplo de como a farda pode condensar uma significação de estorvo e de peso pode ser observado na fala de um policial há 15 anos na polícia Militar (Grupo de Pesquisa "Psicanálise Aplicada e a Prática na Comunidade"):

Em casa, faço questão de primeiramente, antes de tudo, tirar minha farda. Não me sento e não me encosto a nada quando estou com a farda. Quando tiro a farda, é como se tirasse um peso do corpo e da mente. Prefiro deixar no esquecimento que sou policial, em casa tento não ser policial.

A farda é muito mais do que apenas um uniforme. Funciona como um signo de tudo que a corporação representa e acaba por se tornar um catalizador de significações e identificações. No entanto, a modalidade de investimento amoroso, manifestada conscientemente na exaltação dos valores e princípios institucionais com os quais os sujeitos se identificam, não é suficiente para preservar o equilíbrio psíquico de alguns membros do grupo. Os sujeitos que chegaram até o atendimento são os que não correspondem à instituição de forma linear, ao falharem em corresponder à demanda institucional.

O excesso, a farda não absorve. O lado militar, o lado administrativo, o lado ritualesco, a insígnia, não dão conta desse excesso. O que se revela, então, nos atos excessivos, é a violência contida na própria lei, 
quando a farda, os rituais, a hierarquia e a disciplina militar perdem a sustentação, pelo declínio dos ideais e pela ascensão da dimensão do gozo. (Duba, 2012, p. 157)

Ainda que tenha uma poderosa estrutura simbólico-imaginária que visa dar conta do real do dia a dia policial, a farda torna-se um invólucro incapaz de conter tal excesso e não evita ao sujeito o desamparo e a errância de seu gozo, que, como veremos, o leva a construções sintomáticas nefastas e passagens ao ato de extremo dano. Esses policiais são, acima de tudo, os denunciantes de uma estrutura institucional fechada e autoritária que parece negar as dimensões humanas da angústia, do sofrimento e da falta. Em nossa pesquisa, vimo-nos, então, envoltos em relatos que nos remetiam para as questões ligadas às intensidades violentamente inassimiláveis do trauma, do desamparo, da angústia e das passagens ao ato.

\section{O inassimilável e a repetição}

Sabe-se que o trauma é uma ferida narcísica que produz no sujeito uma marca permanente, um corte na narrativa do $\mathrm{Eu}$ e, portanto, nas identificações que o sustentam. Seguindo Lacan (1964/1985) que situou o trauma como o inassimilável, Chemama (1995) define o trauma como um acontecimento que não pode ser assimilado pelo sujeito, apontando assim sua dimensão real, porque impossível de ser simbolizada. Como enfatiza Nestor Braunstein (apud Castro, 2009)

O trauma corta a vida em duas partes: antes e depois. Só que aquele que respira depois não é o mesmo de antes. Um morreu: outro ficou em seu lugar. [...] Aquele que voltou a nascer é um lesado, um sonâmbulo que carrega os restos mortais daquele que não voltará mais. (p. 6)

É nessas vivências de sofrimento extremo, tão presentes nos neuróticos de guerra analisados por Freud (1920/1992e), que encontramos muitos elementos que aproximam a noção de neurose traumática de boa parte dos fenômenos sintomáticos que testemunhamos na clínica com policiais militares. A neurose traumática está intimamente ligada ao conceito de trauma e sua formulação teórica também se dá a partir do enigma que representava, para Freud, estabelecer o que determinaria um evento como traumático. O quadro da neurose traumática se desenvolve em geral do seguinte modo: 


\section{ARTIGOS}

o sujeito vivencia uma experiência traumática num determinado momento e, algum tempo depois, em geral alguns meses mais tarde, começa a ter pesadelos em que a situação do trauma retorna e, além disso, apresenta igualmente flashes diurnos em que ela é alucinada (Cabassut, 2006).

Freud (1919/1992d) postula que na neurose traumática ocorre uma falha na tarefa defensiva do escudo protetor do aparelho psíquico e permite que o mesmo seja invadido com uma carga excessiva de afeto, colocando, dessa maneira, o princípio de prazer - cuja função é diminuir as tensões internas do aparelho psíquico responsáveis pelo desprazer - fora de ação temporariamente. Um dos exemplos bastante significativos e surpreendentes fornecidos por Freud é o do trauma que a criança sofre mediante os cuidados maternos, já que ela ainda não possui um aparelho psíquico minimamente estruturado para sustentar a intensa carga de afeto que a erotização de seu corpo pela mãe desperta. O trauma surge, então, como algo da ordem de um excesso com o qual é impossível lidar. Tal excesso se constitui como algo da ordem de um gozo que excede o prazer e, por isso mesmo, remete ao que Freud denominou de mais além do princípio de prazer: "O trauma inscreve o gozo no corpo e o condena como algo intolerável. Sua impressão recalcada constitui uma cristalização submetida às leis do processo primário, capaz de atrair outras representações intoleráveis" (Mieli, 2002, p. 35).

Frente a esse excesso, a saída do neurótico é, na maioria das vezes, repetir. A compulsão à repetição é o efeito da estratégia de colocar em ato repetido o encontro com o real. Trata-se de duas dimensões diferentes da repetição intimamente relacionadas: o sujeito repete porque não consegue simbolizar e repete para tentar simbolizar. Esta foi a primeira noção de repetição desenvolvida por Freud no contexto de seus "Artigos sobre técnica" (1914/1992c) na relação com a resistência à análise: aquilo que o sujeito não consegue dizer na sessão analítica, ele repete em ato. A segunda noção de repetição foi introduzida por Freud alguns anos mais tarde quando desenvolveu a noção de uma compulsão à repetição que manifesta a ação basal da pulsão de morte, que despreza o princípio de prazer. Se este pretende regular as tensões internas do aparelho psíquico, diminuindo-as de acordo com o princípio de constância, seu mais além visa radicalizar essa tendência e busca zerar tais tensões. Daí Freud ter subsumido esse processo à pulsão de morte e ao que chamou, com Barbara Low, de princípio de Nirvana, pois a vida apresenta sempre alguma tensão e a anulação de todas as tensões é igual à morte.

Cabe aqui fazermos um recorte e evocarmos Lacan e sua teoria sobre a compulsão à repetição, a partir das construções que apresenta no Seminário 
XI. Os quatro conceitos fundamentais da psicanálise, de 1964. No capítulo cinco desse seminário, Lacan faz uso de dois termos gregos do vocabulário de Aristóteles: tiquê e autômaton. Extraídos da noção aristotélica de causa acidental, Lacan (1964/1985) nomeia de autômaton a insistência da cadeia significante em comparecer nas construções que envolvem o retorno do recalcado das formações do inconsciente, sob o registro do princípio de prazer; e de tiquê àquilo que escapa ao princípio de prazer e produz um "encontro do real" (p. 56). A repetição, portanto, pode ser passível de interpretação, se autômaton; e efeito de um encontro faltoso, que extrapola a insistência da cadeia significante, se tiquê. Nas palavras de Lacan (1964/1985) a função da repetição enquanto tique, a saber, "do real como encontro - o encontro enquanto podendo faltar, enquanto essencialmente é encontro faltoso - se apresenta primeiro, na história da psicanálise, de uma forma que, só por si, já é suficiente para despertar nossa atenção - a do traumatismo" (p. 57).

Tiquê será, portanto, a repetição que remete aos efeitos do trauma. É o encontro com o inassimilável, está ligada à pulsão de morte e, por isso, contém em si a verdade do sujeito para além do princípio de prazer.

Com efeito, o trauma é concebido como devendo ser tamponado pela homeostase subjetivante que orienta todo o funcionamento definido pelo princípio de prazer. Nossa experiência nos põe então um problema, que se atém a que no seio mesmo dos processos primários, vemos conservada a insistência do trauma a se fazer lembrar a nós. O trauma reaparece ali, com efeito, e muitas vezes com o rosto desvelado. (Lacan, 1964/1985, p. 57)

A repetição pode, por um lado, estar a serviço de um tratamento do conteúdo traumático de forma a dar uma conotação suportável ao que outrora fora assustador. Como as brincadeiras infantis que mimetizam situações de desamparo ou medo e, ao repetirem a cena em uma brincadeira, possibilitam à criança obter o controle e dirigir o desenrolar da cena de maneira lúdica. Isso ameniza a perplexidade e o desamparo da cena considerada traumática porque dá contorno de palavras e colorido recreativo à experiência. Mas por outro lado, pode servir à neurose traumática, estandarte da falta de simbolização do trauma, por comparecer em sua literalidade crua, atualizando a cada vez a experiência traumática vivida na ocasião original, na tentativa de dar fronteira ao que é da ordem do desamparo. Apesar de Freud (1920/1996e) ser categórico ao afirmar que não crê que a angústia possa gerar uma neurose traumática, a relação entre trauma e angústia é íntima. O ponto de partida para 


\section{ARTIGOS}

que haja angústia é o acontecimento de uma vivência traumática, e a essência disso é uma experiência de desamparo por parte do Eu perante um grande acúmulo de excitação, seja de origem externa ou interna, com a qual não se consegue lidar (Freud, 1926[1925]/1992f).

\section{A angústia}

O conceito de angústia apresentado por Freud no ensaio de $1926^{4}$ traz os efeitos da teoria da pulsão de morte e se articula com a compulsão à repetição, ao desamparo, ao trauma, ao despreparo e ao susto. Passa a ser entendida como uma reação a situações traumáticas. Nessa nova proposição teórica, Freud propõe duas modalidades de angústia: a angústia automática, ligada à situação traumática entendida pelo psiquismo como experiência de desamparo por parte do Eu; e a angústia-sinal, cuja função é defender o Eu das situações de perigo. Nas palavras de Freud (1926[1925]/1992f):

Seguindo essa sequência, angústia - perigo - desamparo (trauma), podemos agora resumir o que se disse. Uma situação de perigo é uma situação reconhecida, lembrada e esperada de desamparo. A angústia é a reação original ao desamparo no trauma, sendo reproduzida depois da situação de perigo como um sinal em busca de ajuda. (p. 161)

Ao investigar o núcleo desse perigo, Freud o localiza em um aumento da tensão longe das fronteiras do tolerável, resultado "de um afluxo de excitações internas que exigem ser liquidadas" (Laplanche \& Pontalis, 2001, p. 526). Essa tensão, então, extravasaria sobre o Eu, que se descobriria desprotegido e à mercê desse excesso, definitivamente desamparado. A saída que o Eu encontraria seria a de converter a angústia automática em angústia sinal, transformando uma situação de desamparo absoluto em uma expectativa ansiosa, uma reprodução mais branda da situação traumática, para que possa controlá-la: "A angústia é, então, por um lado, expectativa de um trauma e, por outro, uma repetição amenizada dele" (Freud, 1926[1925]/1992f, p. 155).

Existem, portanto, dois aspectos da angústia: o primeiro, originado como

${ }^{4}$ Não acreditamos ser necessário expor nesse trabalho a primeira teoria da angústia em Freud, uma vez que nos interessa sua construção teórica a partir de 1920. 
reação ao trauma no momento do incidente e quando o mesmo é rememorado; e o segundo, reproduzido depois, como um sinal. "A angústia não é mais gêmea da sexualidade, mas sim do desamparo" (Rudge, 2009, p. 48).

A angústia, então, passa a ser entendida a partir do desamparo e tem sua origem independente do advento da sexualidade. Ao associar angústia e desamparo, Freud articula desamparo e o defeito constitutivo de nosso aparelho mental na etiologia das neuroses: nossa prematuridade, que diz respeito às condições de dependência em que o bebê humano é colocado no mundo.

Remetendo aos avanços teóricos trazidos pela noção de pulsão de morte, Freud pôde então postular que a angústia é, em última análise, angústia de aniquilação e de morte. A manifestação da angústia é uma espécie de reação à ameaça de desaparecimento do sujeito, causada por alguma situação percebida como traumática e que remete ao desamparo. Tal desamparo pode se estabelecer em qualquer momento da vida, como uma condição de revivência da situação primeira de desamparo do bebê. Os sentimentos angustiantes ligados à castração são apenas uma modalidade da angústia, que se dá diante da perda do amor do objeto ou, em um segundo momento, daquela proveniente do supereu, instância da consciência moral.

$\mathrm{Na}$ neurose traumática a angústia não contorna o traumático que, pelo corpo, fala, expondo ao sujeito que dela sofre seu grande mal-estar. O aparecimento da angústia é efeito do desamparo que o neurótico reatualiza ao experimentar a situação traumática. Contudo, enquanto para Freud a angústia era motivada pela separação da mãe e articulada com o desamparo, para Lacan a teoria toma outra coloração. Como sintetiza Rudge (2009):

Se a criança depende para tudo de sua mãe, o desaparecimento dela é suficiente para mergulhá-la em intensa angústia. Tudo o que desagrada à mãe e poderia constituir uma ameaça de perda de seu amor também passa a ser motivo de angústia. Não é outra a razão que leva a criança a recalcar seus desejos ou pulsões quando pressente que esses poderiam desagradar a quem dela cuida.

[Ernest] Jones e Lacan trouxeram à luz uma nova faceta da angústia, mostrando que a morte psíquica é uma ameaça vinculada não apenas à perda do Outro ou de seu amor, mas também, paradoxalmente, à presença de seu desejo, já que este desejo ameaça reduzir o sujeito à posição de mero objeto. (p. 48)

Lacan (1962-63/2005) dedicou seu décimo seminário à tentativa de construir uma teoria precisa sobre a angústia, no sentido de registrar sua 


\section{ARTIGOS}

posição estrutural, mais do que tentar descrever ou criar uma concepção teórica. Ele retoma a definição de Freud de que a angústia é um afeto cuja posição mínima é a de sinal, mas a subverte ao postular que a angústia não é a manifestação de um excesso perigoso de afluxos de excitações internas ou externas, mas sim o afeto que, numa vacilação, captura o sujeito confrontado com o desejo do Outro. Lacan aposta na presença ameaçadora do desejo do Outro como causa da angústia e afirma que a angústia está relacionada ao temor do sujeito de ser tomado por inteiro pelo desejo do Outro.

Para Lacan, a angústia indica para o sujeito a probabilidade de ser reduzido à posição de objeto do desejo do Outro e apontou a existência de uma estrutura própria. A angústia é um afeto que interessa muito à psicanálise, pois ela serve de orientação ao analista na sua prática, pois norteia para aquilo de mais estranho: Unheimlich. Um "sinal" (Lacan, 1962-63/2005) daquilo que o sujeito evita e, no entanto, define a sua mais pura verdade em relação ao seu desejo. Notadamente o afeto que não engana na direção do tratamento em psicanálise.

No entanto, não se pode ver em Lacan uma concepção de angústia totalmente separada do registro do simbólico, precisamente porque ao pensar em sua estrutura, chama a atenção para o fato de que, contrariando noções anteriores, a angústia se enquadra na relação com o campo do significante, em seu ponto de articulação com o imaginário (Lacan, 1962-63/2005). Porém, nessa articulação, há um resto, no sentido de uma operação matemática de divisão. Esse resultado é o objeto $a$, objeto causa de desejo e representante da falta no imaginário. Trata-se da aproximação com a dimensão do real, ou a "exterioridade estranha ao significante" (Kaufmann, 1996, p. 38). A angústia estaria no registro, portanto, do que sobra da operação de divisão do sujeito, indicando a proximidade com o objeto $a$, no plano do real. E por isso a angústia é o afeto que não engana.

\section{Passagem ao ato}

Se associada ao retorno do recalcado, ensina Lacan, é a angústia sinal nomeada por Freud, que tem como atributo evitar a revivescência de uma situação de desamparo, estado "reanimado quase sempre diante da onipotência do destino cujo enigma em tempos não sombrios, o sujeito vai recobrir com a fantasia" (Fuks, 2001, p. 6) Existe um caráter contingente e único em cada trauma, assim como cada sujeito é único em sua maneira de lidar com o 
traumático. Entre o ser falante e o traumático existe o inconsciente e a fantasia funciona, notadamente, como um anteparo contra tal real traumático. Mas quando essa estratégia não funciona, só resta ao sujeito recorrer ao apagamento que o ato carreia. Ainda no seminário dedicado ao estudo da angústia, Lacan (1962-63/2005) ensina que na passagem ao ato há um apagamento do sujeito, pois quando este atua, busca extrair o objeto $a$ que tampona o furo do Outro e provoca a angústia, reduzindo-se a ele. O sujeito "se precipita e despenca fora da cena" (p. 129). É uma modalidade, como acting out, de evitação da angústia. A relação do ato com o objeto $a$ também produz como efeito do ato uma reconfiguração do Outro e uma relocalização do sujeito, que, no ato, se identificou com o objeto e viu-se fora da cena.

Já em 1967, no seminário dedicado ao Ato Analítico, Lacan (1967-68/2001) coloca o suicídio como paradigma da passagem ao ato. Pois na violência sempre há algo que resta: no exemplo do suicídio é o corpo que cai; há a produção de algo que não fala, mas mostra. Miller (2014) sublinha que "o ato suicida alcança em curto-circuito essa zona central [o bem-estar e a manutenção da existência] e ao mesmo tempo exclui do mundo subjetivo ao qual Lacan deu o nome de gozo (p. 6). E acrescenta:

[...] o termo "passagem ao ato" [...] destaca que se abandonam os equívocos do pensamento, da fala e da linguagem pelo ato. No ato, se o pensamos a partir da passagem ao ato, o sujeito se subtrai, digamos, aos equívocos da fala com toda sua dialética do reconhecimento [...]. No cerne de todo ato há um "Não!" proferido em direção ao Outro. (p. 7)

A passagem ao ato pode ser entendida como uma recusa ao saber: um não querer saber absoluto que culmina em não querer saber nada da barra no campo do Outro, ou seja, da impossibilidade que há no núcleo do saber: $\mathrm{S}(\mathbb{A})$. É a partir da exclusão simbólica que a passagem ao ato carreia que podemos ligá-la à violência.

Violência - outro significante que comparece insistentemente na fala dos policiais. A violência, ensina Lacan, "não é a palavra; inclusive, é exatamente o contrário. $\mathrm{O}$ que se pode produzir em uma relação inter-humana é a violência ou a palavra" (Lacan, 1957-58/1999, p. 471). A violência, então, distingue-se da fala em sua essência. Podemos lançar a hipótese de que um ato violento é aquele que está fora da construção simbólica. Assim, as passagens ao ato se aproximam do trauma por estarem sempre em um "entre", marcado pelo antes e o depois do ato. Podemos até argumentar que toda passagem ao ato é violenta em sua natureza, por causa da ruptura que acarreta. Se 


\section{ARTIGOS}

entendemos a violência como um excesso pulsional ocasionando a ruptura dos laços sociais constituídos no interior de uma cultura, os sujeitos que pudemos ter a chance de escutar a partir de nossa atuação clínica no Batalhão, recorrem à passagem ao ato para tentar dar conta de um transbordamento violento que está além da angústia e impossível de se dizer. A atuação funciona, então, como uma anulação do escoamento do tempo, recorrendo ao tempo de estar morto. Assim, será a passagem ao ato que o sujeito lançará mão para evitar de se haver do que lhe aparece como insuportável. Nas palavras de Benhaim (2011):

[...] uma explosão psíquica — é que a jogada não é o ato, mas antes o próprio sujeito, o sujeito confrontado a um tempo de anulação das representações e dos ideais. Dito de outra maneira, a confrontação ao real, esse impossível que estrutura a realidade, o dentro/fora, o antes/depois, e onde a alteridade poderia ser encarada, não funciona mais. (p. 206)

A passagem ao ato é, então, uma maneira de tratar o insuportável, ali onde nem a farda, nem a angústia e nem a neurose traumática conseguiram obter sucesso. A partir do real que se impõe nas passagens ao ato, é a psicanálise que promove uma torção na maneira de se colocar frente a essas atuações. A psicanálise não coloca seu saber para tamponar o real que os atos denunciam, mas introduz a pergunta sobre o que tais atos poderiam ensinar sobre o trauma. A partir disso, cabe pensar em estratégias para sustentar a possibilidade de uma prática apoiada na psicanálise cuja práxis é " [...] tratar os reais pelo simbólico: o real da angústia, do trauma, do limite, do sonho, da repetição, da pulsão de morte, do impossível, da não relação sexual, do gozo, do caos, da doença psicossomática, da psicose" (Laberge, 2010, p. 46).

A direção da clínica com os policiais passa pelo acolhimento do indizível e, em consequência, em um tratamento de responsabilização por seu próprio saber fazer com o trauma, em movimento oposto à alienação à corporação, na qual o policial se coloca como vitimizado e segregado, impedindo qualquer apropriação subjetiva de seus sintomas. No lugar do ato falho, o ato da fala, da produção fantasística de narrativas possíveis sobre a trama da fantasia esgarçada pelo trauma.

Ao optar eticamente em colocar como agente do seu discurso o que é indizível, a psicanálise se apoia no real, ponto de fuga da referência simbólica, no imponderável que extrapola a possibilidade de apreensão. Pelo acolhimento do indizível é possível convocar a dimensão do ato de dizer como um antídoto para a passagem ao ato. Nossa ação diária 
no manejo com os policiais almeja sustentar um espaço onde, a partir da psicanálise como dispositivo, seja viável dar um tratamento possível para o trauma e a violência, e permitir que cada sujeito possa articular em seu discurso um savoir faire com a violência diária de seu ofício. (Samico, 2016, p. 14)

Narrativas que podem funcionar como construções míticas, nas quais o sujeito pode bordejar com cores libidinais o empuxo ao gozo da pulsão de morte. Aprendemos desde Freud que as fantasias têm essa competência. A fantasia nos é outorgada pelo Outro para que possamos fazer face ao real e sua ação promove um afunilamento, uma parcialização "desse gozo ilimitado que invadia todo o corpo, com a consequente redução de seu gradiente mortífero [...]" (Jorge, 2010, p. 142). A fantasia é o que nos protege das invasões devastadoras do real porque sua tessitura simbólico-imaginária funciona como uma tela protetora, que possibilita o contato com o mundo à nossa volta $\mathrm{e}$ promove os laços sociais. Paola Mieli (2002) argumenta que as Urphantasien, as fantasias originárias descritas por Freud, possuem uma função basilar na maneira como o sujeito suporta o trauma e decifra a própria vida.

[...] essas fantasias - cena primária, fantasia de sedução, fantasia de castração - , transmitidas hereditariamente no seio da herança filogenética do indivíduo, sustentam e confirmam as teorias sexuais infantis; ali onde as teorias sexuais param diante do impensável, as fantasias propõem uma solução e respondem aos enigmas fundamentais relativos à origem [...]. Do mesmo modo que os mitos, as fantasias originárias são construções que expõem a posteriori o conteúdo de um momento precedente; elas fornecem uma explicação a uma causa enigmática subtraída à simbolização. (p. 33)

E se a construção de mitos pessoais e narrativas não é possível, apostamos na engenhosidade do sintoma, que também é uma maneira de tratar o real. Uma vez que não é possível uma representação integral do sujeito pelo significante, a psicanálise ensina que é o sintoma em sua forma mais inequívoca e única para tal sujeito, que lhe permite se haver com seu gozo. "É porque a representação significante só pode liberar um sujeito dividido, é porque jamais se realiza sem produzir uma perda de gozo, que o mais-gozar, aparelhado pelo sintoma, vem funcionar como solução" (Venturini, 2007, p. 179). Nesse sentido, o sintoma apresenta-se como uma solução que se constrói para conciliar o inconciliável (Besset et al., 2006). 


\section{ARTIGOS}

Em nossa atuação no Batalhão, não promovemos o "tratamento" e apostamos na "experiência" psicanalítica. Sem furor sanandis (Freud, 1914[1915]/1992c), podemos finalmente encarnar uma "certa presença, que permite que a operação analítica aconteça, de maneira pura e/ou aplicada" (Mattos, 2003, p. 52). É preciso estar sempre em franco caráter experimental na clínica, mesmo - e talvez sobretudo - quando ela acontece dentro de uma instituição. Nossa prática é e sempre será puntiforme (Lacan, 1976, p. 21) e contingencial. Devemos nos manter sensíveis para o sujeito e suas singularidades, acolhendo a impossibilidade de previsão de resultados. Nossas regras são congruentes com o real que insiste em imprimir seus efeitos em qualquer montagem da cultura do ser falante. Este foi nosso grande aprendizado: acolher a impossibilidade de previsão que toda atuação com o real traz.

[...] a estratégia e a tática da psicanálise aplicada não propõe soluções gerais; cada um responde como pode e como quer, não há fórmula para um final feliz, nem para o bem-estar, no entanto existe uma política, a política do bem dizer, que uma vez alcançada, produz efeitos no mal-estar, com resultados tanto para aquele que encontrou esse bem quanto para a comunidade. (Holck, 2008, p. 24)

Entendemos como sucesso, portanto, a produção de qualquer arranjo simbólico-imaginário que convoque o sujeito para fora do curto-circuito da passagem ao ato. E sustentamos uma atuação na qual há sempre a abstinência de oferta de sentidos, para que nela o próprio sujeito em sofrimento possa criar os seus próprios e, com isso, mudar de lugar, deslocar-se da posição de vítima "acometida pelo trauma". Isso requer o manejo paradoxal tanto da abstenção quanto do acolhimento da demanda de sentido para desfazer o non-sense próprio do trauma. Em última análise, foi preciso pensar as características particulares da direção do tratamento psicanalítico com policiais que apresentam fenômenos que os aproximam da neurose traumática para entender a contingencialidade de um manejo possível para esse teor traumático, de forma que se pudesse acolher esse excesso de gozo presente no testemunho que os policiais trazem sobre seus sintomas.

\section{Referências}

Benhaim, M. (2011). Atuações delinquentes, passagens ao ato suicida 
na adolescência. Ágora: Estudos em Teoria Psicanalítica, 14(2), $197-$ -207. Recuperado em 6 nov. 2017, de: https://dx.doi.org/10.1590/S151614982011000200003.

Besset, V. L., et al. (2006). Trauma e sintoma: da generalização à singularidade. Revista Mal-Estar e Subjetividade, 6(2), 311-331. Recuperado em 12 out. 2017, de http://pepsic.bvsalud.org/scielo.php?script=sci arttext\&pid $=\mathrm{S} 151861482006000200003 \& \operatorname{lng}=\mathrm{es} \& \mathrm{t} \operatorname{lng}=\mathrm{pt}$.

Cabassut, J. (2006). Écrire le réel en psychanalyse? Tese de H.D.R., Nice: Universidade de Nice, Sophia Antipolis.

Castro, S. L. S. (2009). Focalizando o trauma sob as lentes da clínica com policiais militares. Tese de Doutorado em Psicologia Clínica, Pontifícia Universidade Católica do Rio de Janeiro.

Chemama, R. (1995). Dicionário de psicanálise. Porto Alegre, RS: Artes Médicas.

Duba, C. (2012). Comentários. In M. A. Vieira, \& R. do R. Barros (Orgs.), Ódio, segregação e gozo (pp. 153-158). Rio de Janeiro, RJ: Subversos.

Freud, S. (1992a). Introducción del narcisismo. In Obras Completas Sigmund Freud (v. XIV, pp. 65-98). Buenos Aires, Argentina: Amorrortu. (Trabalho original publicado em 1914).

Freud, S. (1992b). Recordar, repetir y reelaborar (Nuevos consejos sobre la técnica del psicoanálisis, II). In Obras Completas Sigmund Freud (v. XVII, pp. $145-$ 158). Buenos Aires, Argentina: Amorrortu. (Trabalho original publicado em 1914).

Freud, S. (1992c). Puntualizaciones sobre el amor de trasferencia (Nuevos consejos sobre la técnica del psicoanálisis, III). In Obras Completas Sigmund Freud (v. XII, pp. 159-174). Buenos Aires, Argentina: Amorrortu. (Trabalho original publicado em 1915 [1914]).

Freud, S. (1992d). Introducción a Zur Psychoanalyse der Kriegsneurosen. In Obras Completas Sigmund Freud (v. XX, pp. 201-214). Buenos Aires, Argentina: Amorrortu. (Trabalho original publicado em 1919).

Freud, S. (1992e). Más allá del principio de placer. In Obras Completas Sigmund Freud (v. XX, pp. 01-62). Buenos Aires, Argentina: Amorrortu. (Trabalho original publicado em 1920).

Freud, S. (1992f). Inhibición, síntoma y angustia. In Obras Completas Sigmund Freud (v. XVIII, pp. 71-164). Buenos Aires, Argentina: Amorrortu. (Trabalho original publicado em 1926[1925]).

Fuks, B. B. (2001). Notas sobre o conceito de angústia. Revista Estudos e Pesquisas em Psicologia, 1(1), 1-9. Recuperado em 7 dez. 2017, de http://www.epublicacoes.uerj.br/index.php/revispsi/article/view/7687/5551. 


\section{ARTIGOS}

Holck, A. L. L. (2008). A psicanálise e a guerra; estratégia, tática e política. In O. M. R. Machado, \& T. Grova. Psicanálise na favela. Projeto Digai-Maré: a clínica dos grupos (pp. 19-24). Rio de Janeiro, RJ: Associação Digaí Maré.

Jorge, M. A. C. (2010). Fundamentos de psicanálise de Freud a Lacan - v. 2: a clínica da fantasia. Rio de Janeiro, RJ: Zahar.

Kaufmann, P. (1996). Dicionário enciclopédico de psicanálise: o legado de Freud e Lacan. Rio de Janeiro, RJ: Zahar.

Laberge, J. (2010) A clínica em Lacan - no Seminário XI (primeira parte). Correio da APPOA, 10(195), 39-48. Recuperado em 12 jan. 2018, de http://www.appoa. com.br/uploads/arquivos/correio/correio195.pdf

Lacan, J. (1976). Conférences et entretiens dans des universités nord-américaines. In Scilicet, 6(7), 5-63. Paris, França: Seuil.

Lacan, J. (1985). O seminário. Livro 11. Os quatro conceitos fundamentais da psicanálise. Rio de Janeiro, RJ: Jorge Zahar. (Trabalho original publicado em 1964).

Lacan, J. (1998). O estádio do espelho como formador da função do eu. In Escritos (pp. 96-103). Rio de Janeiro, RJ: Zahar. (Trabalho original publicado em 1949).

Lacan, J. (1999). O seminário. Livro 5. As formações do inconsciente. Rio de Janeiro, RJ: Jorge Zahar. (Trabalho original publicado em 1957-58).

Lacan, J. (2001). O seminário. Livro 15. O ato psicanalítico. Porto Alegre, RS: Escola de Estudos Psicanalíticos. (Original publicado em 1967-68).

Lacan, J. (2005). O seminário. Livro 10. A angústia. Rio de Janeiro, RJ: Jorge Zahar. (Trabalho original publicado em 1962-63).

Laplanche, J., \& Pontalis, A. (2001). Vocabulário da psicanálise. São Paulo, SP: Martins Fontes

Mattos, S. de. (2003). A disponibilidade do analista. In E.B.P. Escola Brasileira de Psicanálise - Agenda $1^{\circ}$ Semestre 2003 (pp. 52-59). Belo Horizonte, MG: EBP/ Minas

Mieli, P. (2002). Sobre as manipulações irreversiveis do corpo e outros textos psicanalíticos. Rio de Janeiro, RJ: Contra Capa.

Miller, J.-A. (2014). Jacques Lacan: observações sobre seu conceito de passagem ao ato. Opção Lacaniana On-line, 5(13), 1-13. Recuperado em 6 nov. 2017 de http:// www.opcaolacaniana.com.br/pdf/numero_13/passagem_ao_ato.pdf

Muniz, J. (1999). Ser Policial é, sobretudo, uma Razão de Ser. Cultura e Cotidiano da Polícia Militar do Estado do Rio de Janeiro. Tese de Doutorado em Ciência Política, Universidade do Estado do Rio de Janeiro - UERJ, Rio de Janeiro. 
Rudge, A. M. (2009). Trauma. Rio de Janeiro, RJ: Zahar.

Safouan, M. (1993). A palavra ou a morte - como é possivel uma sociedade humana? Campinas, SP: Papirus.

Samico, F. C. (2016). A escuta clínica de policiais militares: violência, trauma e sintoma. Revista Mosaico, 7(2), 10-14. Recuperado em 7 jan. $2018 \mathrm{de} \mathrm{https://doi.}$ org/10.21727/rm.v7i2.46

Venturini, S. (2007). O sintoma e os impasses na análise. Psychê, 11(20), 165-182. Recuperado em 12 nov. 2017 de http://pepsic.bvsalud.org/scielo.php?script=sci arttext\&pid=S1415-11382007000100012\&lng=pt\&tlng=pt.

Wallon, H. (1995). As origens do caráter. São Paulo, SP: Nova Alexandria. (Trabalho original publicado em 1934).

\section{Resumos}

(From the trauma to the possibility of a narrative: notes on psychoanalysis in a Military Police Battalion)

This paper reflects on the experience of the research "Applied Psychoanalysis and the Practice in the Community", based on the clinical service offered to the officers of the 10th Military Police Battalion of Rio de Janeiro State. In it we think about the particular characteristics of the psychoanalytic treatment of policemen, in order to understand the contingency of the possible management for traumatic events, so as to welcome the excess of jouissance present in the testimony that the policemen bring of their symptoms and passages to the act.

Key words: Psychoanalysis, police, trauma, clinic

(Du traumatisme à la possibilité d'un récit: notes sur la psychanalyse dans un bataillon de police militaire)

Cet article traite de l'expérience de la recherche «Psychanalyse appliquée et pratique dans la communauté», à partir des consultations cliniques offertes aux officiers du 10e bataillon de police militaire de l'État de Rio de Janeiro. On y réfléchit aux particularités du traitement psychanalytique avec les policiers, afin de comprendre la contingence d'une prise en charge possible du traumatisé, afin d'accueillir l'excès de joie présent dans le témoignage que les policiers font de leurs symptômes et passages à l'acte.

Mots clés: Psychanalyse, police, traumatisme, clinique 


\section{ARTIGOS}

(Del trauma a la posibilidad de una narrativa: notas sobre el psicoanálisis en un Batallón de Policía Militar)

Este artículo reflexiona sobre la experiencia de la investigación "Psicoanálisis aplicado y la práctica en la comunidad", desde la atención clínica ofrecida a los policías del $10^{\circ}$ Batallón de Policía Militar del Estado de Río de Janeiro. En él, se examinan las características particulares del tratamiento psicoanalítico de policías para comprender la contingencialidad del posible manejo del trauma, de forma que se acoja el exceso de goce presente en el testimonio que los policías traen sobre sus sintomas y sus pasos al acto.

Palabras clave: Psicoanálisis, policía, traumatismos,clínica

(Von Trauma zur Möglichkeit einer Erzählung: Notizen zur Psychoanalyse in einem Militärpolizeibataillon)

Dieser Artikel befasst sich mit den Erfahrungen, die während eines Studienprojekts "Angewandte Psychoanalyse und Praxis in der Gemeinschaft" gesammelt wurden, anhand klinischer Sitzungen, die den Offizieren des 10. Militärpolizeibataillons des Staates Rio de Janeiro angeboten wurden. Wir beschreiben und erwägen die besonderen Merkmale der psychoanalytischen Behandlung mit Polizeibeamten, um die Kontingenz der möglichen Behandlung für das Traumatische zu verstehen, um so dem Übermaß an Genuss Rechnung zu tragen, dass sich in den Aussagen der Beamten über ihre Symptome und die Umsetzung in die Tat manifestiert.

Schlüsselwörter: Psychoanalyse, Polizei, Trauma, Klinik

Citação/Citation: Samico, F. C. M., \& Coutinho Jorge, M. C. (2018, setembro). Do trauma à possibilidade de uma narrativa: notas sobre a psicanálise em um Batalhão de Polícia Militar. Revista Latinoamericana de Psicopatologia Fundamental, 21(3), 568-588. http://dx.doi. org/10.1590/1415-4714.2017v21n3p568.9.

Editores do artigo/Editors: Profa. Dra. Ana Maria Rudge e Profa. Dra. Sonia Leite.

Recebido/Received: 5.6.2018/ 6.5.2018 Aceito/Accepted: 29.7.2018 / 7.29.2018

Copyright: (c) 2009 Associação Universitária de Pesquisa em Psicopatologia Fundamental/ University Association for Research in Fundamental Psychopathology. Este é um artigo de 
livre acesso, que permite uso irrestrito, distribuição e reprodução em qualquer meio, desde que o autor e a fonte sejam citados / This is an open-access article, which permits unrestricted use, distribution, and reproduction in any medium, provided the original authors and sources are credited.

Financiamento/Funding: Os autores declaram não terem sido financiados ou apoiados / The authors have no support or funding to report.

Conflito de interesses/Conflict of interest: Os autores declaram que não há conflito de interesses / The authors have no conflict of interest to declare.

\section{Fernanda Cabral Samico}

Psicanalista; doutoranda em Clínica e Pesquisa em Psicanálise pelo Programa de Pós-graduação em Psicanálise do Instituto de Psicologia da Universidade do Estado do Rio de Janeiro - UERJ (Rio de Janeiro, RJ. Br); Professora do curso de Psicologia e do curso de Medicina da Universidade de Vassouras (Vassouras, RJ, Br.).

fesamico@gmail.com

\section{Marco Antônio Coutinho Jorge}

Psicanalista; Psiquiatra; Professor Associado da Universidade do Estado do Rio de Janeiro - UERJ (Rio de Janeiro, RJ. Br); Membro da Associação Brasileira de Psiquiatria (Rio de Janeiro, RJ, Br); Membro da Sociedade Internacional de História da Psiquiatria e da Psicanálise; Membro da Associação Insistance (Paris, França); Diretor do Corpo Freudiano Escola de Psicanálise - seção Rio de Janeiro (Rio de Janeiro, RJ, Br).

macjorge@corpofreudiano.com.br

This is an open-access article, which permits unrestricted use, distribution, the original authors and sources are credited. 